\title{
Jahrestagung 2007
}

Die Vereinigung der Deutschen Staatsrechtslehrer veranstaltete ihre Jahrestagung 2007 vom 3. bis 6. Oktober in Freiburg i. Br.; damit fand nach 1961 wieder einmal eine Staatsrechtslehrertagung in Freiburg i. Br. statt. Die Tagung 2007 fiel für die dortige Universität in ein Jubiläumsjahr; die Albert-Ludwigs-Universität feierte im Jahr 2007 ihr 550. Gründungsjubiläum. Etwa 530 Personen nahmen an der Tagung teil, davon knapp 400 Kolleginnen und Kollegen, über 100 Begleitpersonen sowie zahlreiche ausländische Gäste und Vertreter von juristischen Verlagen.

In der Mitgliederversammlung am 3. Oktober 2007 wurde zu Beginn der seit der letzten Jahrestagung verstorbenen Mitglieder gedacht: Görg Haverkate und Christian-Friedrich Menger; die Vereinigung wird ihnen ein ehrendes Andenken bewahren. Seit der letzten Jahrestagung wurden 17 neue Mitglieder in die Vereinigung aufgenommen; sie zählt nunmehr 669 Mitglieder. Die Mitgliederversammlung beschloss, der Vereinigung die Rechtsform eines eingetragenen Vereins zu geben.

Das wissenschaftliche Programm stand unter dem Generalthema „Die Leistungsfähigkeit der Wissenschaft des Öffentlichen Rechts“. Die acht Berichte zu den vier Themenstellungen behandelten das Verfassungsrecht zwischen normativem Anspruch und politischer Wirklichkeit sowie vor den Herausforderungen der Globalisierung, das Verwaltungsrecht zwischen klassischem dogmatischen Verständnis und steuerungswissenschaftlichem Anspruch sowie die Entwicklung eines Internationalen Verwaltungsrechts als Aufgabe der Rechtswissenschaft. Während bei der Tagung in Rostock 2006 die Themenstellung auf die europarechtliche Perspektive ausgerichtet war, wurden zentrale Fragen des Öffentlichen Rechts bei der Tagung 2007 um die Dimension des Völkerrechts ergänzt und erweitert. Die von Herrn Pieroth und Herrn F. Kirchhof geleiteten Aussprachen erlebten Diskussionen auf hohem wissenschaftlichen Niveau mit vielen weiterführenden Beiträgen; die Freiburger Tagung hat ein eindrucksvolles Zeugnis zur Leistungsfähigkeit der Wissenschaft des Öffentlichen Rechts präsentiert. Der am Mittwochvormittag tagende Gesprächskreis „Europäisches Verfassungsrecht“ behandelte das Thema „Grundrechtsschutz im Zusammenspiel von EU, EMRK und nationalem Verfassungsrecht"; der parallel stattfindende Gesprächskreis „Verwaltung“ befasste sich am Beispiel der Landesverwaltung und der Hochschulverwaltung mit der Thematik „Verwaltungsreform als Verwaltungsaufgabe: Akteure, Mechanismen, Instrumente“.

Das Rahmenprogramm umfasste zunächst eine von Mitgliedern der Freiburger Rechtswissenschaftlichen Fakultät und von Historikern veranstaltete Stadtführung, die mit einem beeindruckenden Orgelkonzert im 
Freiburger Münster verbunden war. Auf große Resonanz stießen auch die am Donnerstag und Freitag im Rahmenprogramm veranstalteten Ausflüge in die Region um Freiburg und in das nahe gelegene Colmar. Am Mittwochabend gaben der Rektor der Albert-Ludwigs-Universität Freiburg und der Oberbürgermeister der Stadt Freiburg gemeinsam einen Empfang in der Aula der Universität. Der Empfang des Ministerpräsidenten des Landes Baden-Württemberg fand am Donnerstagabend im Freiburger Konzerthaus statt. Am Freitagabend versammelten sich die Tagungsteilnehmer zu einem Festdiner in der Mensa der Universität.

Der traditionelle Ausflug am Samstag führte bei „Kaiserwetter“ in den Schwarzwald. Die Landschaft zeigte sich bei strahlendem Sonnenschein von ihrer schönsten Seite, Teilnehmer am Ausflug sprachen von einer ,geradezu atemberaubenden Schönheit" des Südschwarzwaldes. Einen wahren Kunstgenuss stellten die Führungen im Kloster und in der Kirche von St. Peter sowie im Dom zu St. Blasien dar. Die direkt am Titisee eingelegte Mittagspause fuigte sich vortrefflich in das Programm des Ausflugs ein.

Der besondere Dank der Vereinigung gilt Herrn Kollegen Würtenberger, den der Vorstand kooptiert hatte. Herr Würtenberger hat mit seinen Mitarbeiterinnen und Mitarbeitern die Jahrestagung 2007 vorzüglich vorbereitet und organisatorisch begleitet. Die Teilnehmer der Jahrestagung waren vom reibungslosen Ablauf sehr angetan und haben dies mehrfach zum Ausdruck gebracht. Insgesamt wird die Freiburger Tagung den Teilnehmern als gelungene Veranstaltung mit reichem wissenschaftlichen Ertrag in Erinnerung bleiben. 